\title{
High Resolution EELS Investigation Of Hexagonal Transition Metal Perovskites
}

C. Maunders, ${ }^{* * *}$ H. Whitfield, ${ }^{*, * *}$ G. Radtke, ${ }^{* * *}$ G.A. Botton, ${ }^{* * *, * * * *}$ S. Lazar, ${ }^{* * * * *}$ and J. Etheridge*

* School of Physics and Materials Engineering, Monash University, Victoria, Australia

** CSIRO Manufacturing and Infrastructure Technology, Clayton, Victoria, Australia

${ }^{* * *}$ Brockhouse Institute for Materials Research, McMaster University, Hamilton, Ontario

${ }^{* * * *}$ National Centre for High Resolution Electron Microscopy, Dept of Technical Sciences, Kavli Inst. for Nanoscience, TU Delft, The Netherlands

It is well established that the substitution of $\mathrm{Ti}$ in $\mathrm{BaTiO}_{3}$ to give $\mathrm{Ba}_{3} \mathrm{Ti}_{2} \mathrm{MO}_{9}$, where $\mathrm{M}=$ $\mathrm{Ti}^{3+}, \mathrm{V}, \mathrm{Cr}, \mathrm{Mn}, \mathrm{Fe}, \mathrm{Co}, \mathrm{Ru}, \mathrm{Rh}, \mathrm{Ir}, \mathrm{Pt}$, can stabilise the high temperature $6 \mathrm{H}$ hexagonal structure at room temperature [1]. The work presented here is a comparative study of the structure and bonding in two of these compounds, $\mathrm{Ba}_{3} \mathrm{Ti}_{2} \mathrm{RuO}_{9}$ and $\mathrm{Ba}_{3} \mathrm{Ti}_{2} \mathrm{MnO}_{9}$, with a view to understanding their structure-property relationships and the mechanism by which the $6 \mathrm{H}$ structure is stabilized at room temperature. Using convergent beam electron diffraction (CBED) we have shown that the space group of both compounds is the non-centrosymmetric $\mathrm{P}_{3} \mathrm{mc}$ [2]. In this paper, we report the results so far of our investigation into the bonding of these and related compounds using high resolution electron energy loss spectroscopy (HREELS).

Experiments were performed on the world's first commercial monochromated field emission gun transmission electron microscope [3] with a high-resolution electron energy loss spectrometer [4]. The nominal energy resolution of $0.1 \mathrm{eV}$ combined with an electron probe diameter of less than $2 \mathrm{~nm}$, permits the detection of fine features in the near edge structure of the EEL spectrum from small volumes of specimen. This enables us to probe electronic structure effects from nanoscale specimen volumes.

Using this instrument, we have observed the different electronic configurations of the $\mathrm{Ru}$ and $\mathrm{Mn}$ ions in $\mathrm{Ba}_{3} \mathrm{Ti}_{2} \mathrm{RuO}_{9}$ and $\mathrm{Ba}_{3} \mathrm{Ti}_{2} \mathrm{MnO}_{9}$ by examining the O-K edge (FIG. 1) in their EEL spectra. A striking difference is evident in the intensity of the band covering the transition metal $t_{2 g}-\mathrm{O} 2 p$ hybrid states in these otherwise very similar spectra. The hybrid $\mathrm{Mn} \mathrm{t}_{2 \mathrm{~g}}-\mathrm{O} 2 \mathrm{p}$ is present as a small shoulder on the O-K edge onset in $\mathrm{Ba}_{3} \mathrm{Ti}_{2} \mathrm{MnO}_{9}$ but the $\mathrm{Ru} \mathrm{t}_{2 \mathrm{~g}}-\mathrm{O} 2 \mathrm{p}$ hybrid appears to be in the same energy range as the $\mathrm{Ti}$ $\mathrm{t}_{2 \mathrm{~g}} \mathrm{O} 2 \mathrm{p}$ energy level in the $\mathrm{Ba}_{3} \mathrm{Ti}_{2} \mathrm{RuO}_{9}$ compound. $\mathrm{Mn}$ is expected to be in 4+ oxidation state with a high spin configuration with $3 \mathrm{~d}$ electrons in the $\mathrm{t}_{2 \mathrm{~g}}$ sublevel and $\mathrm{Ru}^{4+}$ is low spin with $4 \mathrm{~d}$ electrons in the $t_{2 \mathrm{~g}}$ sublevel. The different occupancies in the $\mathrm{t}_{2 \mathrm{~g}}$ lead to a greater transition probability into the $\mathrm{Mn}_{2 \mathrm{~g}} \mathrm{O} 2 \mathrm{p}$ band. These results are consistent with a crystal field theory interpretation of $\mathrm{Ru}$ and $\mathrm{Mn}$ ions in a perfect oxygen octahedral field.

We have also observed that the distortion of the oxygen octahedra surrounding the $\mathrm{Ti}$ ions in $\mathrm{Ba}_{3} \mathrm{Ti}_{2} \mathrm{MnO}_{9}, \mathrm{Ba}_{3} \mathrm{Ti}_{2} \mathrm{RuO}_{9}$ and tetragonal $\mathrm{BaTiO}_{3}$ is highly comparable. This is indicated by the consistency of the relative heights and widths of the $t_{2 g}$ and $e_{g}$ peaks between all three spectra on the $\mathrm{Ti}_{2,3}$ edges (FIG. 2). The octahedral configuration of the oxygen atoms around the $\mathrm{Ti}$ atoms breaks the $\mathrm{Ti} \mathrm{d}$ orbital degeneracy into two sublevels, $\mathrm{t}_{2 \mathrm{~g}}$ and $\mathrm{e}_{\mathrm{g}}$ through hybridisation. The width of the $\mathrm{e}_{\mathrm{g}}$ peak on the $\mathrm{Ti} \mathrm{L}_{2,3}$ edge thus reflects the octahedral distortion around the $\mathrm{Ti}$ ion. This observation supports the suggestion that the $6 \mathrm{H}$ structure is stabilised at room temperature due to the distortion of the octahedral symmetry of the face sharing octahedra. 
Density functional theory calculations, using the Wien $2 \mathrm{k}$ code, of the O-K edges will also be presented here.

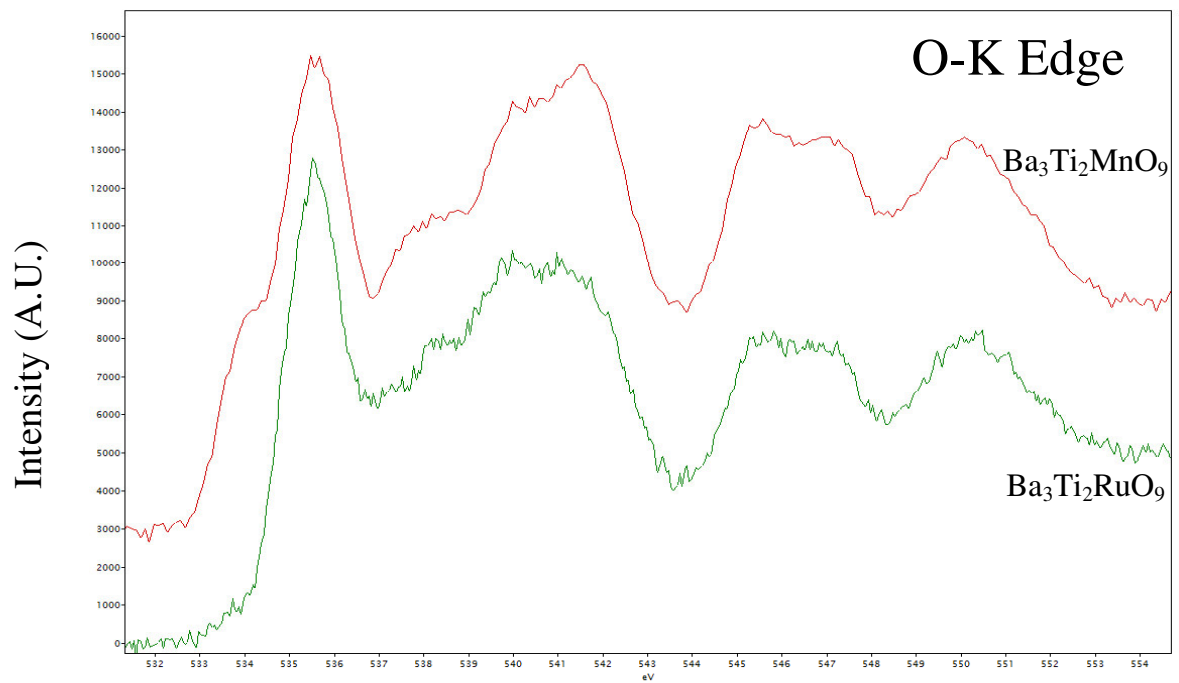

Energy Loss (eV)

FIG. 1. Comparison between O-K edges in $\mathrm{Ba}_{3} \mathrm{Ti}_{2} \mathrm{MnO}_{9}$ and $\mathrm{Ba}_{3} \mathrm{Ti}_{2} \mathrm{RuO}_{9}$.

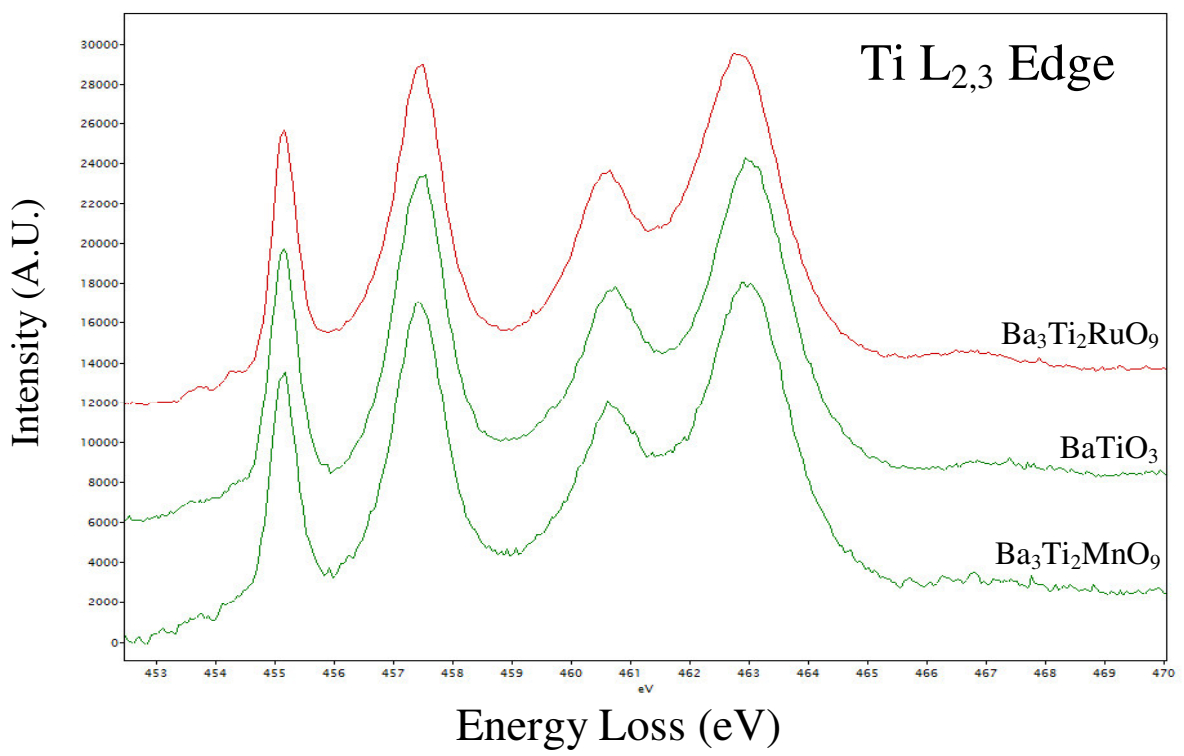

FIG. 2. Comparison between $\mathrm{Ti} \mathrm{L}_{2,3}$ edges in $\mathrm{Ba}_{3} \mathrm{Ti}_{2} \mathrm{MnO}_{9}$ and $\mathrm{Ba}_{3} \mathrm{Ti}_{2} \mathrm{RuO}_{9}$ and tetragonal $\mathrm{BaTiO}_{3}$.

\section{References}

[1] J. G. Dickson, L.K., Roland Ward, J. Am. Chem. Soc, 83 (1961), 3026-3029.

[2] C. Maunders, J. Etheridge, N. Wright, H. J. Whitfield, Acta. Cryst. B, In Press.

[3] P.C. Tiemeijer, J.H.A. van Lin, A.F. de Jong., Microscopy and Microanalysis, 2 (2001) 1130-1131.

[4] H.A. Brink et al., Microscopy and Microanalysis 7, 2 (2001) 908-909. 